Glasgow Caledonian

University

University for the Common Good

\title{
Urinary incontinence in men after formal one-to-one pelvic-floor muscle training following radical prostatectomy or transurethral resection of the prostate (MAPS): two parallel randomised controlled trials
}

Glazener, Cathryn; Boachie, Charles; Buckley, Brian; Cochran, Claire; Dorey, Grace; Grant, Adrian; Hagen, Suzanne; Kilonzo, Mary; McDonald, Alison; McPherson, Gladys

Published in:

Lancet

DOI:

$10.1016 / \mathrm{S} 0140-6736(11) 60751-4$

Publication date:

2011

Document Version

Author accepted manuscript

Link to publication in ResearchOnline

Citation for published version (Harvard):

Glazener, C, Boachie, C, Buckley, B, Cochran, C, Dorey, G, Grant, A, Hagen, S, Kilonzo, M, McDonald, A \& McPherson, G 2011, 'Urinary incontinence in men after formal one-to-one pelvic-floor muscle training following radical prostatectomy or transurethral resection of the prostate (MAPS): two parallel randomised controlled trials', Lancet, vol. 378, no. 9788, pp. 328-337 . https://doi.org/10.1016/S0140-6736(11)60751-4

\section{General rights}

Copyright and moral rights for the publications made accessible in the public portal are retained by the authors and/or other copyright owners and it is a condition of accessing publications that users recognise and abide by the legal requirements associated with these rights.

Take down policy

If you believe that this document breaches copyright please view our takedown policy at https://edshare.gcu.ac.uk/id/eprint/5179 for details of how to contact us. 
Title

2 Urinary incontinence in men after prostate surgery (MAPS): two randomised controlled trials

3 of formal one-to-one pelvic floor muscle training after radical prostatectomy or TURP.

4

5 Clinical Trial registration number: ISRCTN87696430

6 Link to published protocol: http://www.thelancet.com/protocol-reviews/07PRT-588

\section{Authors with degrees}

9 Cathryn Glazener $\mathrm{PhD}^{1^{*}}$, Charles Boachie $\mathrm{MSc}^{1}$, Brian Buckley $\mathrm{PhD}^{2}$, Claire Cochran $\mathrm{MSc}^{1}$,

10 Grace Dorey $\mathrm{PhD}^{3}$, Adrian Grant $\mathrm{DM}^{4}$, Suzanne Hagen $\mathrm{PhD}^{5}$, Mary Kilonzo $\mathrm{MSc}^{6}$, Alison

11 McDonald MSc ${ }^{1}$, Gladys McPherson $\mathrm{MSc}^{1}$, Katherine Moore $\mathrm{PhD}^{7}$, John Norrie MSc(Econ) ${ }^{8}$,

12 Craig Ramsay $\mathrm{PhD}^{1}$, Luke Vale PhD, ${ }^{6}$ James N'Dow FRCS(Urol) ${ }^{9}$

$14{ }^{1}$ Health Services Research Unit, University of Aberdeen, Foresterhill, Aberdeen, AB25 22D, 15 UK

$16{ }^{2}$ Bladder and Bowel Foundation, SATRA Innovation Park, Kettering NN16 9JH, UK

$17{ }^{3}$ Faculty of Health and Life Sciences, The University of the West of England, Bristol, BS16 18 1DD, UK

$19{ }^{4}$ College of Life Sciences and Medicine, University of Aberdeen, Foresterhill, Aberdeen, 20 AB25 22D, UK

$21{ }^{5}$ Nursing, Midwifery and Allied Health Professions Research Unit, Glasgow Caledonian

22 University, Cowcaddens Road, Glasgow, G4 OBA, UK

$23{ }^{6}$ Health Economics Research Unit, University of Aberdeen, Foresterhill, Aberdeen, AB25 24 22D, UK

$25{ }^{7}$ Faculty of Nursing, University of Alberta, Edmonton, Canada

$26{ }^{8}$ Robertson Centre for Biostatistics, University of Glasgow, Boyd Orr Building University 27 Avenue, Glasgow, G12 8QQ, UK

$28{ }^{9}$ Academic Urology Unit, University of Aberdeen, Foresterhill, Aberdeen, AB25 22D, UK

*Corresponding author: Cathryn Glazener

\section{Conflict of interest}

33 Disclosure forms provided by the authors are available. 
Abstract

Urinary incontinence (UI) is common immediately after prostate surgery. Men are often advised to perform pelvic floor exercises, but evidence to support this is inconclusive. The Men After Prostate Surgery (MAPS) study consisted of two randomised controlled trials testing whether formal one-to-one pelvic floor muscle training reduces incontinence. Methods

Men who were incontinent six weeks after radical prostatectomy (Trial 1) or transurethral resection of the prostate (TURP, Trial 2) were randomly assigned, using remote computer allocation, to four sessions with a Therapist over three months (intervention group, $\mathrm{N}=205$, 220 respectively), or standard care and lifestyle advice only (control group, $\mathrm{N}=206,222$ ). The primary endpoints, collected via postal questionnaires, were participants' report of UI, and incremental cost per quality-adjusted life year (QALY) after 12 months. Outcome assessors were blinded to group assignment, but this was not possible for participants or caregivers. Recruitment was completed in September 2008.

\section{Findings}

In the intervention group in Trial 1 (radical prostatectomy), the UI rate at 12 months was not significantly different compared with the control group: $75.5 \%$ (148/196, intervention) versus $77.4 \%$ (151/195, control): absolute risk difference (RD) $-1.9 \%$ [-10\% to $6 \%]$.

In Trial 2 (TURP), the difference in the UI rate at 12 months was not statistically significant: $126 / 194,64.9 \%$ in the intervention group versus $125 / 203,61.5 \%$ in the control group, RD $3.4 \%$ [-6\% to $13 \%]$. Adjusting for minimisation factors or performing 'treatment received' analyses did not change these results in either trial. No adverse effects were reported. In both trials, the intervention resulted in higher mean costs per patient ( $£ 180$ and £209 respectively) but there was no evidence of an economically important difference in QALYs (differences: 0.002 and 0.00003).

In settings where information about pelvic floor exercise is currently widely available, one-toone conservative physical therapy for men who are incontinent after prostate surgery is unlikely to be effective or cost-effective. The high rates of persisting incontinence after one year indicate a significant level of unrecognised and unmet need for management amongst these men.

67

Clinical Trial registration number: ISRCTN87696430

\section{Funding}

National Institute of Health Research, Health Technology Assessment (NIHR HTA) 
Radical prostatectomy (RP) is a key treatment in localised (early stage) prostate cancer and may be performed by open surgical approaches (retropubic or less frequently, perineal) or by minimally invasive techniques using laparoscopic or robotic technologies. Men with lower urinary tract symptoms secondary to benign prostatic enlargement (BPE) who fail to respond to medical therapy are treated surgically by transurethral resection of the prostate (TURP). Although newer technologies continue to emerge, TURP remains the standard and most cost effective approach.(1-3)

86

Both groups of men are at risk of post-operative urinary incontinence (UI). Radical prostatectomy is associated with high rates, recently reported at around $16 \%$ at one year following surgery.(4;5) TURP for BPE is associated with a much lower prevalence of incontinence, $9 \%$ initially(1) and around $1 \%$ at 12 months postoperatively,(6) but as the operation is performed much more frequently, this still presents a significant public health burden.

Effectiveness of pelvic floor muscle training (PFMT) in women is relatively well established. $(7 ; 8) \quad$ Analogous advice to perform pelvic floor muscle exercises is a typical early management strategy for men with stress UI after prostatectomy, but successive updates of Cochrane reviews concluded that there was insufficient evidence to demonstrate its effectiveness and hence cost-effectiveness.(9) Men who undergo TURP more often have overactive bladder syndrome or urgency urinary incontinence: bladder training (BT) is often recommended for these conditions, again without clear evidence of efficacy.(10) program with BT if indicated delivered in four one-to-one sessions, with current care that does not include formally taught PFMT. The primary outcome was UI reported by men at 12 months after randomisation. 


\section{Study Design}

118 Men having prostate surgery were identified in 34 centres in the United Kingdom (UK) and 119 invited to receive a screening questionnaire three weeks after surgery. Those who reported

$120 \mathrm{UI}$ in their 'Screening' questionnaire were invited to be randomised. However, formal trial 121 entry was limited to those men who were still incontinent as judged by their response to a 122 further 'Baseline' questionnaire. This second questionnaire also contributed wider descriptive 123 data as reported in Table 1. The methods were identical in the two parallel but separate trials

124 (Trial 1 after radical prostatectomy and Trial 2 after TURP for BPE).

126 Randomisation was by remote computer allocation using the randomisation service of the 127 Centre for Healthcare Randomised Trials (CHaRT, Health Services Research Unit, 128 University of Aberdeen). Allocation was minimised based on centre, age and pre-existing 129 UI. The process was independent of all clinical collaborators.

131 Participants and therapists could not be masked to the intervention. Outcome assessment 132 was by participant-completed questionnaires and diaries, and data were entered by clerical 133 staff blinded to group allocation.

\section{Participants}

136 Men were eligible if they had UI at six weeks after surgery for either prostate cancer or BPE. 137 Incontinence was defined as any positive response to either of two screening questions from 138 the International Consultation on Incontinence Questionnaire Urinary Incontinence Short 139 Form (ICIQ-UI SF) questionnaire.(11) Participants needed to be able to comply with the 140 intervention and complete study questionnaires. Men were excluded if they had been 141 referred for or received formal PFMT. Men who had TURP for lower urinary tract symptoms 142 secondary to advanced prostate cancer ('channel TURP') or were to receive radiotherapy 143 were excluded as these factors might independently affect bladder function or continence 144 mechanisms.

\section{Interventions}

147 All randomised men received a Lifestyle Advice Leaflet that described the influence of fluid 148 intake, caffeine, diet, constipation, fitness, lifting, chest problems and urinary tract infections 149 on continence. No information was provided in the leaflet about pelvic floor exercises or 150 techniques for dealing with urgency symptoms. Men having radical prostatectomy are 151 commonly told about pelvic floor exercises by health care professionals and information is 152 also widely available in the public domain, for example through the internet. No attempt was 
made to prevent any participants from accessing such information independently, or from

154 leaflets if these were part of standard care.

Men randomised to the intervention groups were invited to attend four one-to-one sessions held over a period of three months with a therapist and received a supplementary MAPS Pelvic Floor Exercise leaflet, aimed at establishing a home exercise regimen. The therapists were either specialist continence physiotherapists or specialist continence or urology nurses. Therapists were provided with standardised training in the management of male UI based on PFMT and BT. Details of the intervention and its rationale are described elsewhere.(12) Men in the control groups were not invited to one-to-one therapy and did not receive the MAPS Pelvic Floor Exercise leaflet.

\section{Outcome measurements}

166 The primary clinical endpoint was men's report of UI at 12 months after randomisation using 167 the ICIQ-UI SF, a simple validated patient-completed instrument.(11) Incontinence was 168 defined as any positive response to either of two screening questions from the ICIQ-UI SF 169 questionnaire:(11) 'how often do you leak urine?' and 'how much urine do you leak? The 170 primary measure of cost-effectiveness was incremental cost per quality-adjusted life year 171 (QALY). Data at trial entry were collected by postal questionnaires and a 3-day urinary 172 diary, and outcome data were collected by postal questionnaire and diary at 3, 6, 9 and 12 months after randomisation.

Data collected included: urinary outcomes (using the ICIQ-UI SF which measures frequency and severity of incontinence, the effect of incontinence on quality of life as a composite ICIQ score, the presence and type of incontinence)(11); use of pads and catheters; daytime and night time urinary frequency and incontinence; quality of life (EQ-5D and SF-12); use of health services in both primary and secondary care; QALYs derived from responses to the

180 EQ-5D (13); and frequency of the practice of pelvic floor exercises. Data were also collected on bowel outcomes (such as faecal incontinence) and sexual function (such as erectile function). Data for all other secondary outcomes will be published in a forthcoming HTA Monograph.

\section{Sample size and statistical analysis}

186 We identified that achieving a difference of $15 \%$ in incontinence rates would be of clinical 187 importance. Therefore, we aimed to identify an absolute difference between intervention 188 and control groups of $15 \%(85 \%$ versus $70 \%)$ in the number of men who were still 189 incontinent at 12 months: 174 men per arm of each trial would be needed to give $90 \%$ 190 power to detect a statistically significant difference at the $5 \%$ level. This would also allow the 
detection of a difference equivalent to 0.30 of a standard deviation for continuous measures,

192 such as quality of life, with $80 \%$ power. Allowing for dropout after enrolment, we planned to recruit 200 men per arm of each trial.

195 Descriptive statistics were tabulated reporting baseline demographics and clinical 196 characteristics using means and standard deviations (SD). We did not impute missing 197 values for non-responders to questionnaires or diaries.

199 Intention-to-treat analyses (men analysed according to randomised group) were used to 200 compare the primary outcome at 12 months using general linear models adjusting for age 201 and pre-existing $\mathrm{UI}$ and trial entry data where appropriate. For the binary outcomes, a 202 Poisson link function was used to estimate relative risks and robust standard errors were used to estimate the confidence intervals.(14) A secondary comparison was conducted to estimate the efficacy of the treatment received using a latent variable approach ('adjusted treatment received') (15) by the method described by Nagelkerke and colleagues.(16)

Planned subgroup analyses explored the effect on the primary outcome of potentially effectmodifying factors, such as pre-surgery incontinence, type of incontinence and type of therapist (physiotherapy or nursing background). Stricter levels of statistical significance $(2 \mathrm{P}<0.01)$ were sought, reflecting the exploratory nature of these analyses.

\section{Economic evaluation}

213 The economic evaluation was a within-trial analysis at 12 months after recruitment. Direct

214 health service costs associated with each treatment were derived by combining data on use

215 of health services with unit cost data extracted from the literature or from relevant 216 sources(17-20) to generate the total cost for each participant. QALYs were generated using 217 the responses to the EQ-5D.

Mean costs for both intervention and control groups were compared using unpaired t tests and linear regression adjusted for data measured at trial entry. Non-parametric bootstrapping was used to estimate confidence limits. Differences in mean QALYs were estimated in a similar fashion and incremental cost-effectiveness ratios calculated, where appropriate.

\section{Ethical approval}

226 This trial was approved by the Multicentre Research Ethics Committee, Edinburgh, Scotland, and overseen by an independent trial steering committee and a separate independent data monitoring committee. All men gave signed informed consent to being screened, and 
229 separately to being randomised: the trial was conducted in accordance with the Declaration

230 of Helsinki.

231

232 Funding

233 The trial was funded by the National Institute of Health Research, Health Technology 234 Assessment (NIHR HTA) Programme (project number 03-14-03) and will be published in full 235 in Health Technology Assessment. The funder of the study had no role in study design, data 236 collection, data analysis, data interpretation or writing of the report.

237

238 Author information

239 All authors agreed to submit the manuscript to the Lancet. Data was accessible to CB, CR, 240 MK, LV, GMcP.

241

242

243

244

245

246 
249 Between January 2005 and September 2008, in 34 UK centres, we approached 1158 men having a radical prostatectomy of whom 780 met the inclusion criteria for screening and $95 \%$ (742/780) responded to the screening questionnaire. We also approached 5986 men having a TURP: of 2838 eligible for screening, 91\% (2588/2838) responded. Of those eligible for randomisation at around six weeks after surgery, 87\% (411/472) entered the radical prostatectomy RCT (Trial 1) and 86\% (442/512) entered the TURP RCT (Trial 2, Figures $1 \mathrm{~A}$ and $1 \mathrm{~B})$. Follow up rates for the primary outcome were high (95\% (391/411) in Trial 1 and 90\% (397/442) in Trial 2). No important clinical or demographic differences were identified between the randomised groups at entry in either trial (Table 1).

\section{Exercise behaviour and treatment compliance}

260 Many men had prior knowledge of pelvic floor exercises (380/411, 92\%in Trial 1 and $183 / 442,41 \%$ in Trial 2): $84 \%$ (346/411) of men in the former and $21 \%(93 / 442)$ in the latter claimed to be performing them at six weeks after operation but before randomisation (Table 1). Of the men allocated to the intervention groups, 189/205 (92\%) and 189/220 (86\%) respectively attended at least one therapy visit, while 175 (85\%) and 158 (72\%) respectively attended until the final visit (Table 4, though not necessarily all four appointments). Men in the intervention groups were more likely to report carrying out exercises at 12 months (Table 2): Trial 1: 128/191 (67\%) versus 95/189 (50\%), adjusted risk ratio (RR) 1.30 [95\% Cl 1.09 to 1.53 ]; Trial 2: $122 / 188$ (65\%) versus 39/193 (20\%), adjusted RR 3.20 [2.37 to 4.32].

\section{Urinary outcomes after radical prostatectomy (Trial 1)}

At 12 months, $75.5 \%$ (148/196) of the intervention group and $77.4 \%(151 / 195)$ of the control group reported some UI, absolute Risk Difference (RD) $-1.9 \%$ [-10\% to $6 \%$, far short of the pre-specified target difference of $15 \%$ (Table 3). Adjusting for minimisation factors or performing a 'treatment received' analysis did not change these results (Table 3).

\section{Urinary outcomes after TURP (Trial 2)}

277 At 12 months, 64.9\% (126/194) of the intervention group and 61.6\% (125/203) of the control group reported some UI, absolute RD 3.4\% [-6\% to 13\%], again, far short of the prespecified target difference of $15 \%$ (Table 3). Adjusting for minimisation factors or performing a 'treatment received' analysis did not change these results (Table 3).

In both trials, there were no statistically significant differences in the prevalence of UI or the mean ICIQ score between the groups at any of the time points (Figures 2, 3), nor in any of the other outcomes related to urinary leakage (Table 2). The majority of the improvement in 
continence occurred within three months of trial entry (Figure 3). There was no evidence of

286 a difference between trial groups in effect on faecal incontinence or erectile function (data not shown), or in any of the pre-specified subgroups (Figure 4).

\section{Economic evaluation after radical prostatectomy (Trial 1)}

290 The UK NHS provides universal health care coverage with care free at the point of use. The

291 total trial-related NHS cost (interventions and subsequent NHS care) per participant was

292 statistically significantly higher in the intervention group (difference estimate $£ 181$ [95\% Cl

$293 £ 107$ to £255], US\$287, [95\% Cl \$170 to \$404]).(21) This was almost entirely due to the

294 cost of the one-to-one PFMT. On average, QALYs were virtually identical in the trial groups

295 (difference: 0.002, [95\% Cl -0.027 to 0.023]), giving a mean incremental cost per QALY of $296 £ 90,510$ (US\$143,458).

297

\section{Economic evaluation after TURP (Trial 2)}

299 The trial-related cost (interventions and the cost of subsequent NHS care) per participant 300 was statistically significantly higher in the intervention group (difference estimate £209 [95\% $301 \mathrm{Cl} £ 147$ to $£ 271$ ], US\$332 [95\% Cl \$233 to \$430]) almost entirely due to the cost of PFMT.

302 On average, the QALYs were lower for the intervention although not statistically significantly $303(-0.00003[95 \% \mathrm{Cl}-0.026$ to 0.026$])$. On average the intervention was dominated because it was more costly and there was no evidence that it was any more effective.

\section{Adverse effects}

307 No adverse effects were reported by any participant in the trials.

\section{Overall incontinence rates}

310 At six weeks after radical prostatectomy, 59\% (429/742) of men reported incontinence

311 (Figure 1a). Amongst the 411 randomised incontinent men, the rate of incontinence a year 312 later, irrespective of management and assuming non-responders were dry, was 73\% (299

313 men incontinent, Table 2). Of the original total population of $742 \mathrm{men}$, this translates to $40 \%$ 314 (299) with any incontinence a year after radical prostatectomy (20\% (152) severe, 18\% (131) 315 wearing pads). As expected, the incontinence rate at trial entry six weeks following TURP 316 was lower (17\%: 442/2590, Figure $1 b$ ), but of the 442 randomised men, $57 \%(251)$ were still 317 wet 12 months later (Table 2). Of the original total population of 2590 men, this translates to 318 10\% (251/2590) still wet a year after TURP (4\% (97/2590) severe, 2\% (48/2590) wearing 319 pads). 


\section{Summary of main findings}

325 While the provision of one-to-one PFMT for men with UI after radical prostatectomy or TURP 326 increased the number of men reporting they were performing pelvic floor exercises 327 (compared to the control groups) in both trials, it did not result in better short or medium term 328 continence rates or quality of life. It was significantly more costly to the NHS. Hence, 329 provision of one-to-one PFMT was not cost-effective for UI after either radical prostatectomy 330 or TURP in the UK health care context, where advice to perform pelvic floor exercises is 331 widely available through other less intensive channels, such as verbally, in leaflets or via 332 internet.

Stress urinary incontinence was more common after radical prostatectomy and urgency incontinence more common after TURP (Table 1). We treated the two populations as separate trials because of these clinical differences. Nevertheless, we did not find evidence of benefit of the intervention for either clinical group.

\section{Strengths and weaknesses}

341 The findings were consistent and robust. Validated outcome measures were used to assess men's subjective report of UI and pad use: arguably, these subjective outcomes are most relevant to men.(11) Independent of the statistical methods used to compare the groups, all the outcome measures concurred in failing to find clinically or statistically significant differences between the randomised groups in each trial. Where statistically significant differences in costs were identified, these were due to the higher cost of providing the intervention rather than any consequences of the intervention.

The randomised groups were comparable at trial entry on clinical and demographic characteristics (Table 1). The radical prostatectomy trial (Trial 1) included 87\% (411/472) of the men who were still incontinent six weeks later and therefore eligible to be randomised. Similarly, the TURP trial (Trial 2) included 86\% (442/512) of the men still eligible. These high participation rates, and the large number of UK centres contributing participants, suggest that the findings are generalisable to men with $\mathrm{UI}$ after radical prostatectomy or TURP in settings where information on PFMT is already available and accessed by men.

All men were analysed in the groups to which they were randomised. Once randomised, participants were compliant in attending treatment and in returning their questionnaires, 
360 dropout from the randomised groups (Figures 1a and b), and incontinence rates remained

361 similar even if the men lost to follow up were all assumed to be dry. This provided

362 reassurance that the outcome data were representative of the men included in the trials, and

363 that bias from differential attrition was minimal. We chose not to use objective measures of

364 incontinence, such as pad tests, because of practical difficulties but, more importantly,

365 because we felt that the men's rating of their incontinence was the more important clinical

366 outcome.(22) The data entry was by clerks blinded to randomisation thus minimising

367 detection bias. It was not possible to blind men or therapists to trial allocation. Performance

368 of PFMT was reported by the men themselves in questionnaires, and thus may have been

369 biased if they over-reported how many times they were expected to perform them rather

370 than their actual practice. This information could not be verified objectively but was only

371 used as a measure of the effect of attendance at therapy sessions on changing behaviour.

372

373 It is important to note that MAPS has not tested whether PFMT itself is an effective and

374 efficient way of reducing incontinence in men. In the current health care system where

375 information about incontinence after prostatectomy and PFMT is freely available, it would not

376 be possible to identify a control group which was unaware of pelvic floor exercises.

378 The methods of the economic analysis were rigorous and reproducible. Although not reported in full here, we assessed the importance of uncertainties surrounding estimates of costs, effects and cost-effectiveness, and the conclusions were robust to these.

\section{Meaning of the study}

383 Despite the men's high attendance rate at therapy visits and self-reported adherence to performance of PFMT at home, there was no corresponding difference in UI rates in either clinical group. In contexts where advice to men about PFM exercise is widely available, this may be sufficient to instruct men in PFMT and adopt other behaviours aimed at improving their post-surgery continence. This trial found no extra benefit from the provision of one-toone sessions with a therapist focusing on pelvic floor exercises and other aspects of conservative care such as BT and lifestyle advice for incontinent men after radical prostatectomy or TURP. There was also no evidence to suggest a different conclusion in sub-groups of men, such as those with pre-surgery incontinence, different types of incontinence or those receiving PFMT from a trained continence nurse rather than a trained physiotherapist (Figure 4).

The frequency of delivery of the intervention (four times in three months combined with home exercises) is typical of standard care in the NHS, and most men attended for the 
of contact with therapists after surgery, ranging from five sessions over 16 weeks (23), to three times a week for three weeks (24), to weekly as long as the incontinence persisted (25), there is little evidence that more frequent contacts in men would result in better incontinence outcomes.(9) However, the aim of therapy in all trials is to teach and motivate the men to perform pelvic floor exercises every day: MAPS showed that this was successful in both trials $(128 / 191,67 \%$ performing them in Trial 1, and 122/188, 65\% in Trial 2, compared with $95 / 189,50 \%$ and $39 / 193,20 \%$ in the respective control groups, Table 2). The timing of the intervention (starting six weeks postoperatively) was dictated by the terms of the HTA commissioning brief, but it could be argued that starting earlier or before surgery would result in unnecessary treatment of men who would become dry spontaneously.

Before randomisation, there were considerably fewer men in the control group in the TURP trial performing PFMT compared to amongst the men after radical prostatectomy. This probably reflects the information supplied to men and the attitudes of staff around the time of prostate surgery. The underlying risk of becoming incontinent was much lower in the TURP group, so it may be that health professionals were less likely to recommend PFMT to men after TURP and indeed only around 40\% (183/442) of men were aware of them, compared to over $90 \%$ (380/411) of men after radical prostatectomy. As a result, men in the Radical

416 group were four times more likely to be actually performing PFMT before randomisation.

417 The type of incontinence may also have affected the chance of men performing PFMT: this 418 is recommended for stress urinary incontinence but men after TURP were more likely to 419 have urgency urinary incontinence (Table 1). However, interestingly, the men in the 420 intervention groups in both trials were equally likely to report that they were still performing PFMT at 12 months (around 65\%).

We have only limited information about putative mechanisms for any effects of the 424 intervention through men's reports of performing exercises and their daily frequency. 425 Although we did see differential effects on these, the intervention might also be expected to 426 have wider effects, such as improving the quality rather than the quantity of pelvic floor muscle contractions, the use of broader behavioural techniques such as BT, and generic quality of life, which were not measured directly.

429 The incontinence rates extrapolated to the original populations of men having prostatectomy 430 (20\% severe after radical prostatectomy and 10\% after TURP) concur with those reported in 431 recent surveys of quality of life after radical prostatectomy $(4 ; 5)$ and the $9 \%$ reported in a 432 meta-analysis of RCTs of TURP compared with alternative surgical treatments for BPE.(1)

\section{Conclusions}


435 In settings where information about pelvic floor exercises is widely available, the provision of 436 one-to-one conservative therapy for men with $\mathrm{UI}$ after radical prostatectomy or TURP is 437 unlikely to be effective or cost-effective. Resources currently allocated to providing such a 438 service might be better used elsewhere.

439

440 Research is needed to identify the best management for the large numbers of men who are 441 left with persistent severe incontinence after radical prostatectomy, particularly the place of 442 continence surgery for men. Similarly, research is needed to identify the best management 443 for men with persistent incontinence following TURP.

444

445 


\section{Acknowledgements}

447 The MAPS study group would like to thank all the men who willingly participated in the

448 MAPS trial and completed their questionnaires, diaries and attended their therapy

449 appointments. We are also very grateful to the staff at each of our centres for recruiting and

450 motivating our participants.

451

452 Thanks to the MAPS Study Office staff (Louise Campbell, Diane Collins, Janice Cruden and 453 Julie Murdoch) for administration of the trial.

\section{Disclaimer}

456 The trial was funded by the National Institute of Health Research Health Technology 457 Assessment Programme, Project number 03-14-03. HSRU, HERU and NMAHP RU are 458 funded by the Chief Scientist Office of the Scottish Government Health Directorates. 459 However, the views expressed in this publication are those of the authors and not 460 necessarily those of the funding bodies or the Department of Health, UK. The authors 461 accept full responsibility for the research.

462

\section{Appendix}

464 Recruiting sites and Principal Investigators (MAPS Study group)

465

466

\section{References}

467

Pages 34-35

468

469

\section{Research in Context}

470

\section{Systematic Review Panel:}

472 The trial was commissioned because a Cochrane review in 1999 concluded that there was

473 no reliable evidence on which to base treatment. The most recent update of this review (9)

474 found six relevant RCTs but was still inconclusive, and only one trial (26) provided 12-month 475 outcomes. The addition of MAPS to this review resulted in a Risk Ratio for urinary 476 incontinence at 12 months of $0.97,95 \% \mathrm{Cl} 0.87$ to 1.09 . A subsequent search of the

477 Cochrane Incontinence Review group's register of trials found one more small trial (27) that 478 provided outcomes at 12 months, but it had unexplained differential dropout from the control 479 group. The addition of this trial introduced significant heterogeneity and widened the 480 confidence interval (RR $0.92,95 \% \mathrm{Cl} 0.81$ to 1.03 ). 
484 MAPS is the largest trial of formal one-to-one PFMT amongst men with urinary incontinence 485 after radical prostatectomy, and the only trial in men incontinent after TURP. Of two other 486 trials after radical prostatectomy, the results of one (26) were consistent with MAPS with 487 similar rates of incontinence in the two trials groups at 12 months; the other smaller trial (27) 488 showed lower rates of incontinence in the PFMT group but with high differential loss to 489 follow-up.

490

491

492 


\section{Contributions of Authors}

494 Professor Cathryn Glazener (Professor of Health Services Research, Chief Investigator), was the chief investigator of the study: she had complete involvement and oversight of the study design, execution and data collection, and was responsible for the writing of the final

497 report.

498 Mr Charles Boachie (Statistician, statistical analysis) contributed to the statistical analysis of 499 the study and writing of the results and discussion chapters.

500 Dr Brian Buckley (Chairman, Bladder and Bowel Foundation, consumer representative) contributed to the consumer aspect of the study and writing the final report. Mrs Claire Cochran (Trial Manager) was responsible for the day to day management of the study and also contributed to the final report writing.

504 Professor Grace Dorey (Professor, The University of the West of England, intervention specialist) contributed to the design of the intervention component of the study, and was also responsible for training the therapists recruited to provide the intervention to study participants.

Professor Adrian Grant (Director of Research, trialist) contributed to the overall study design and gave expert guidance on the final report writing.

510 Professor Suzanne Hagen (Programme Director, trial design) contributed to the design of

511 the study and also to the choice and design of the outcomes measures.

512 Miss Mary Kilonzo (Research Fellow, health economics) contributed to the analysis of the

513 health economics component of the study and also to the writing of the health economics 514 chapters.

515 Mrs Alison McDonald (Senior Trial Manager, trialist) contributed to the design of the study,

516 organised the authorisation of the study and contributed to the writing of the final report.

517 Mrs Gladys McPherson (Senior IT Manager, programming) designed the programming of the 518 study database, data analysis and writing of the final report.

519 Professor Katherine Moore (Vice Dean, trialist and therapist perspective) contributed to the 520 design of the therapy intervention and to the writing of the final report. 
521 Professor John Norrie (Director of ChaRT) contributed to the design, running and

522 interpretation of the study,

523 Dr Craig Ramsay (Healthcare Assessment Programme Director, HSRU, statistical analysis)

524 contributed to the statistical analysis of the study and also to the writing of the results 525 chapters.

526 Professor Luke Vale (Professor of Health Technology Assessment, HERU, health 527 economics) contributed to the writing of the health economics chapters and to the 528 interpretation of the health economics findings.

529 Professor James N'Dow (Professor of Urology, clinician) contributed his clinical expertise to 530 the design of the study and to the final report writing. 


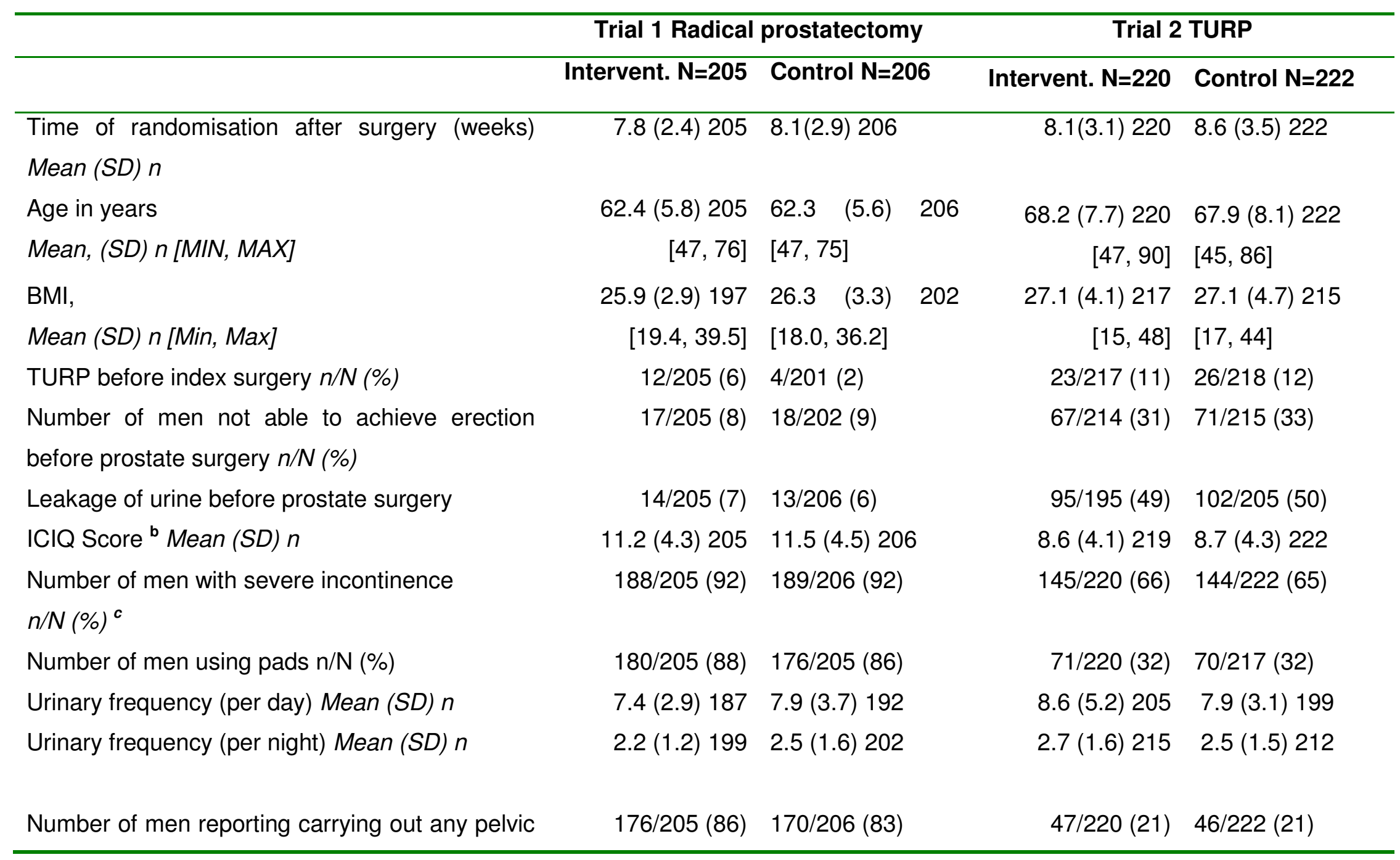




\begin{tabular}{|c|c|c|c|c|c|c|}
\hline \multicolumn{7}{|c|}{ floor exercises before randomisation } \\
\hline \multicolumn{3}{|c|}{ EQ-5D Mean (SD) $n$} & $0.8(0.2) 200$ & $0.8(0.2) 206$ & $0.8(0.3) 213$ & $0.8(0.3) 213$ \\
\hline \multicolumn{3}{|c|}{ SF-12 Mental Mean (SD) $n$} & $50.8(10.5) 201$ & $49.3(10.7) 201$ & $49.9(10.4) 216$ & $50.3(10.4) 212$ \\
\hline \multicolumn{3}{|c|}{ SF-12 Physical Mean (SD) n } & $42.7(9.9) 201$ & $41.8(10.6) 201$ & $42.7(11.0) 216$ & $43.2(11.9) 212$ \\
\hline \multicolumn{7}{|c|}{ Type of incontinence $n / N(\%)$} \\
\hline \multicolumn{3}{|c|}{ SUI } & 195/205 (95) & 195/206 (95) & $148 / 220(67)$ & $136 / 222(61)$ \\
\hline \multicolumn{3}{|c|}{ UUI } & $135 / 205(66)$ & $156 / 206(76)$ & $186 / 220(85)$ & $183 / 222(82)$ \\
\hline \multicolumn{3}{|c|}{ MUI (both) } & $132 / 205(64)$ & $151 / 206(73)$ & $129 / 220(59)$ & $112 / 222(50)$ \\
\hline \multicolumn{3}{|c|}{ Post-micturition leakage } & $166 / 205(81)$ & 170/206 (83) & $151 / 220(69)$ & $156 / 222(70)$ \\
\hline \multicolumn{3}{|c|}{ Other type of incontinence } & $72 / 205(35)$ & $91 / 206(44)$ & $57 / 220(26)$ & $44 / 222(20)$ \\
\hline \multirow{2}{*}{\multicolumn{2}{|c|}{ Type of operation }} & \multicolumn{2}{|l|}{ a } & Type of operation & \multicolumn{2}{|c|}{ TURP $n / N(\%)$} \\
\hline & & \multicolumn{2}{|c|}{204205} & \multicolumn{3}{|c|}{220222} \\
\hline & Abdominal & $157 / 204(77)$ & $161 / 205(79)$ & Standard TURP & $210 / 220(95)$ & 207/222 (93) \\
\hline & Perineal & $6 / 204(3)$ & $4 / 205(2)$ & Laser TURP e & $10 / 220(5)$ & $15 / 222(7)$ \\
\hline & Laparoscopic $^{d}$ & $41 / 204(20)$ & 40/205 (20) & & & \\
\hline$a$ & \multicolumn{6}{|c|}{ Information missing in 2 cases } \\
\hline b & \multicolumn{6}{|c|}{ ICIQ Score: $0=$ none, 21 = maximum (worst) score } \\
\hline c & \multicolumn{6}{|c|}{ Severe incontinence defined as at least once a day AND a moderate or large amount of leakage on ICIQ-UI SF.(11) } \\
\hline$d$ & \multicolumn{6}{|c|}{ No procedures were performed robotically } \\
\hline e & \multicolumn{6}{|c|}{ No procedures involved holmium enucleation (HoLEP) } \\
\hline
\end{tabular}


Table 2

Outcomes at 12 months

\begin{tabular}{|c|c|c|c|c|c|c|}
\hline & \multicolumn{3}{|c|}{ Trial 1 Radical prostatectomy } & \multicolumn{3}{|c|}{ Trial 2 TURP } \\
\hline & $\begin{array}{r}\text { Intervent. } \\
\mathrm{N}=205\end{array}$ & $\begin{array}{l}\text { Control } \\
\mathrm{N}=206\end{array}$ & $\begin{array}{c}\text { RR or MD }[95 \% \mathrm{Cl}] \\
\text { p-value }\end{array}$ & $\begin{array}{r}\text { Intervent. } \\
\mathrm{N}=\mathbf{2 2 0}\end{array}$ & $\begin{array}{l}\text { Control } \\
\mathrm{N}=222\end{array}$ & $\begin{array}{c}\text { RR or MD }[95 \% \mathrm{Cl}] \\
\text { p-value }\end{array}$ \\
\hline \multicolumn{7}{|c|}{ Incontinence outcomes } \\
\hline $\begin{array}{l}\text { Men with any } \\
\text { incontinence }^{\text {a }}\end{array}$ & $148 / 196(76)$ & $151 / 195(77)$ & $\begin{array}{c}0.97[0.87 \text { to } 1.09] \\
0.64\end{array}$ & $126 / 194(65)$ & $125 / 203(62)$ & $\begin{array}{c}1.06[0.91 \text { to } 1.23] \\
0.47\end{array}$ \\
\hline \multicolumn{7}{|l|}{$n / N(\%)$} \\
\hline $\begin{array}{l}\text { Men with severe } \\
\text { incontinence }^{b}\end{array}$ & 74/196 (38) & $78 / 195(40)$ & $\begin{array}{c}0.93[0.73 \text { to } 1.19] \\
0.58\end{array}$ & $48 / 194(25)$ & 49/203 (24) & $\begin{array}{c}1.03[0.73 \text { to } 1.45] \\
0.88\end{array}$ \\
\hline \multicolumn{7}{|l|}{$n / N(\%)$} \\
\hline $\begin{array}{l}\text { ICIQ Score at } 12 \\
\text { months }^{c}\end{array}$ & $4.9(4.1) 196$ & $5.4(4.5) 195$ & $\begin{array}{c}-0.34[-1.05 \text { to } 0.38] \\
0.36\end{array}$ & $3.9(3.7) 194$ & $4.0(4.3) 203$ & $\begin{array}{c}-0.04[-0.78 \text { to } 0.71] \\
0.93\end{array}$ \\
\hline \multicolumn{7}{|l|}{ Mean $(S D) n$} \\
\hline $\begin{array}{l}\text { Number of men } \\
\text { using pads } \\
n / N(\%)\end{array}$ & $63 / 196(32)$ & 68/195 (35) & $\begin{array}{c}0.91[0.69 \text { to } 1.20] \\
0.50\end{array}$ & 24/194 (12) & $24 / 203(12)$ & $\begin{array}{c}1.05[0.62 \text { to } 1.78] \\
0.86\end{array}$ \\
\hline $\begin{array}{l}\text { Daytime urinary } \\
\text { incontinence } \\
\text { episodes from } \\
\text { diaries }\end{array}$ & $1.7(3.3) 183$ & $1.7(2.7) 181$ & $\begin{array}{c}0.04[-0.65 \text { to } 0.72] \\
0.92\end{array}$ & $1.4(2.3) 175$ & $1.2(2.2) 179$ & $\begin{array}{c}0.21[-0.30 \text { to } 0.72] \\
0.42\end{array}$ \\
\hline
\end{tabular}




\begin{tabular}{|c|c|c|c|c|c|c|}
\hline \multicolumn{7}{|l|}{ Mean (SD) $n$} \\
\hline $\begin{array}{l}\text { Nocturnal urinary } \\
\text { incontinence } \\
\text { episodes from } \\
\text { diaries }\end{array}$ & $0.2(0.6) 183$ & $0.2(0.8) 181$ & $-0.05[-0.27$ to 0.16$] 0.62$ & $0.4(0.9), 175$ & $0.4(0.9) 179$ & $\begin{array}{c}0.03[-0.25 \text { to } 0.32] \\
0.81\end{array}$ \\
\hline Mean $(S D) n$ & & & & & & \\
\hline \multicolumn{7}{|l|}{$\begin{array}{l}\text { Type of } \\
\text { incontinence }\end{array}$} \\
\hline \multicolumn{7}{|l|}{$n / N(\%)$} \\
\hline SUI & $138 / 196(70)$ & $128 / 195(66)$ & 1.071 [0.94 to 1.22$] 0.31$ & 71/194 (37) & $76 / 203(37)$ & $0.91[0.72$ to 1.17$] 0.48$ \\
\hline UUI & $61 / 196(31)$ & $83 / 195(43)$ & $0.782[0.61$ to 1.00$] 0.05$ & 72/194 (37) & $82 / 203(40)$ & $0.92[0.72$ to 1.17$] 0.48$ \\
\hline MUI (both) & $59 / 196(30)$ & $74 / 195(38)$ & $0.843[0.65$ to 1.10$] 0.21$ & 46/194 (24) & $58 / 203(29)$ & $0.77[0.56$ to 1.06$] 0.12$ \\
\hline $\begin{array}{c}\text { Post- } \\
\text { micturition leakage }\end{array}$ & $102 / 196(52)$ & $106 / 195(54)$ & $0.924[0.73$ to 1.17$] 0.51$ & $92 / 194(47)$ & $87 / 203(43)$ & $1.13[0.92$ to 1.39$] 0.25$ \\
\hline $\begin{array}{l}\text { Other type } \\
\text { of incontinence }\end{array}$ & $39 / 196(20)$ & $39 / 195(20)$ & $1.099[0.74$ to 1.63$] 0.64$ & $18 / 194(9)$ & 17/203 (8) & 1.04 [0.55 to 1.95$] 0.91$ \\
\hline $\begin{array}{l}\text { Urinary frequency } \\
\text { (per day) }\end{array}$ & $6.8(2.1) 184$ & $7.0(2.8) 183$ & $-0.24[-0.73$ to 0.26$] 0.35$ & $7.0(4.3) 177$ & $6.5(2.1) 178$ & $0.35[-0.40$ to 1.09$] 0.36$ \\
\hline Mean $(S D) n$ & & & & & & \\
\hline
\end{tabular}




\begin{tabular}{|c|c|c|c|c|c|c|}
\hline $\begin{array}{l}\text { Urinary frequency } \\
\text { (per night) } \\
\text { Mean }(S D) n\end{array}$ & $1.3(1.0) 180$ & $1.4(1.0) 185$ & $-0.04[-0.21$ to 0.14$] 0.68$ & $1.7(1.4) 177$ & $1.8(1.6) 181$ & $-0.05[-0.30$ to 0.20$] 0.70$ \\
\hline $\begin{array}{l}\text { Number of } \\
\text { contractions per } \\
\text { day } \\
\text { Mean }(S D) n\end{array}$ & $12(20) 191$ & 19 (79) 189 & $\begin{array}{c}-7.80[-19.43 \text { to } 3.901] \\
0.19\end{array}$ & $11(23) 188$ & $4(16) 193$ & $\begin{array}{c}6.88[2.91 \text { to }-10.86] \\
0.0007\end{array}$ \\
\hline $\begin{array}{l}\text { Number of men } \\
\text { with faecal } \\
\text { incontinence } \\
n / N(\%)\end{array}$ & $16 / 193(8)$ & $11 / 193(6)$ & $\begin{array}{c}1.56[0.74 \text { to } 3.29] \\
0.24\end{array}$ & $40 / 192(21)$ & $36 / 199(18)$ & $\begin{array}{c}1.06[0.74 \text { to } 1.52] \\
0.75\end{array}$ \\
\hline
\end{tabular}




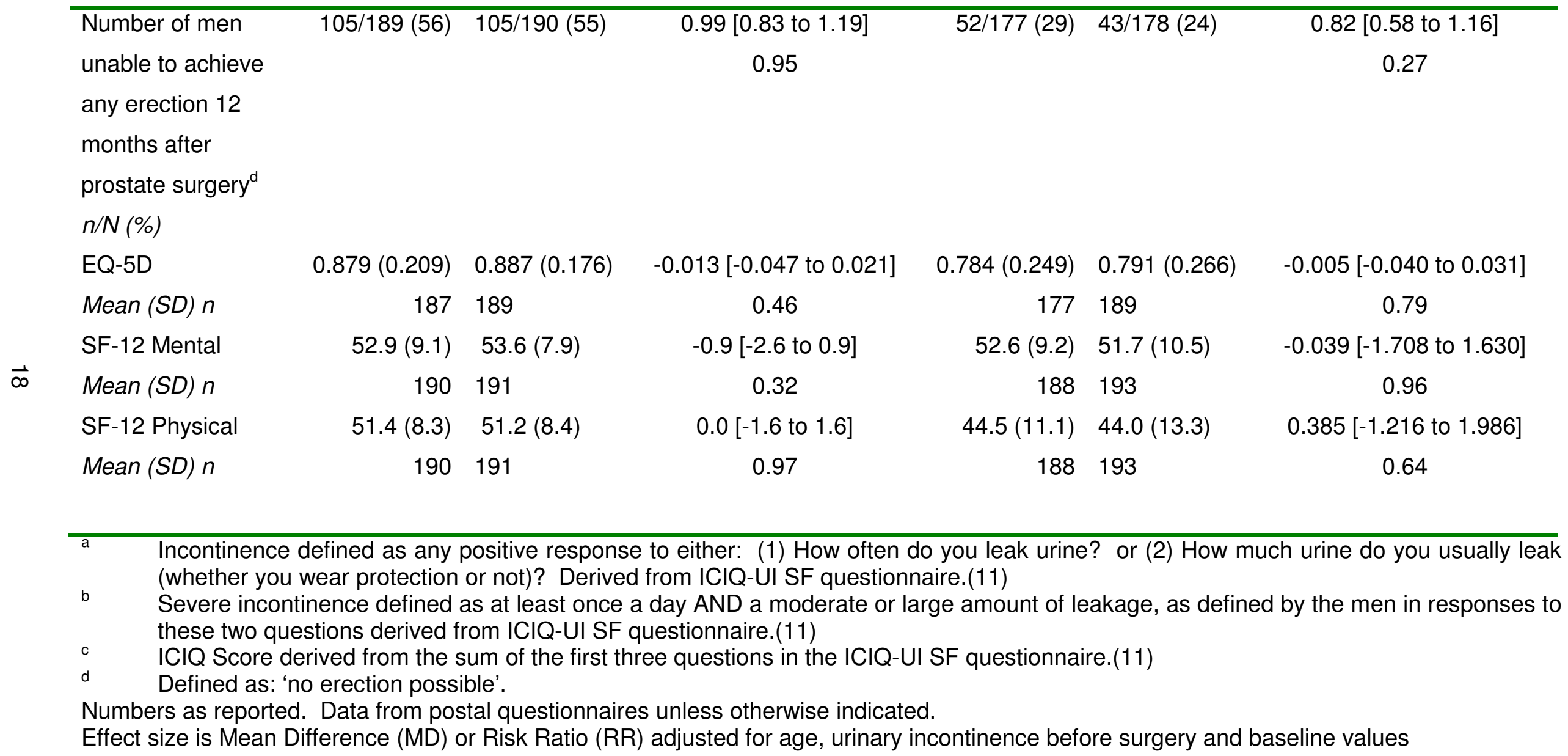

$\begin{array}{rlcrl}0.879(0.209) & 0.887(0.176) & -0.013[-0.047 \text { to } 0.021] & 0.784(0.249) & 0.791(0.266) \\ 187 & 189 & 0.46 & 177 & 189 \\ 52.9(9.1) & 53.6(7.9) & -0.9[-2.6 \text { to } 0.9] & 52.6(9.2) & 51.7(10.5) \\ 190 & 191 & 0.32 & 188 & 193 \\ 51.4(8.3) & 51.2(8.4) & 0.0[-1.6 \text { to } 1.6] & 44.5(11.1) & 44.0(13.3) \\ 190 & 191 & 0.97 & 188 & 193\end{array}$

$-0.005[-0.040$ to 0.031$]$

0.79

-0.039 [-1.708 to 1.630$]$

0.96

0.385 [-1.216 to 1.986$]$

0.64

SF-12 Physical

Incontinence defined as any positive response to either: (1) How often do you leak urine? or (2) How much urine do you usually leak (whether you wear protection or not)? Derived from ICIQ-UI SF questionnaire.(11)

b Severe incontinence defined as at least once a day AND a moderate or large amount of leakage, as defined by the men in responses to these two questions derived from ICIQ-UI SF questionnaire.(11)

c ICIQ Score derived from the sum of the first three questions in the ICIQ-UI SF questionnaire.(11)

d Defined as: 'no erection possible'.

Numbers as reported. Data from postal questionnaires unless otherwise indicated.

Effect size is Mean Difference (MD) or Risk Ratio (RR) adjusted for age, urinary incontinence before surgery and baseline values 
Table 3

Primary outcome, urinary incontinence at $\mathbf{1 2}$ months: further statistical analyses

\begin{tabular}{lrr}
\hline & Trial 1 Radical prostatectomy & Trial 2 TURP \\
\hline Urinary incontinence at 12 months & $148 / 196(75.5 \%$, intervention) & $126 / 194(64.9 \%$, intervention) \\
$\mathrm{n} / \mathrm{N}(\%)$ & $151 / 195(77.4 \%$, control) & $125 / 203(61.5 \%$, control) \\
Absolute Risk Difference $[95 \% \mathrm{Cl}]$ & $-1.9 \%[-10 \%$ to $6 \%]$ & $3.4 \%[-6 \%$ to $13 \%]$ \\
\hline
\end{tabular}

\section{Risk Ratio $[95 \% \mathrm{Cl}]$ p-value Risk Ratio [95\% Cl] p-value}

\section{Intention to treat}

Unadjusted analysis

$$
\begin{array}{ll}
0.98 \text { [0.88 to } 1.09] 0.72 & 1.05[0.91 \text { to } 1.22] 0.49 \\
0.97[0.87 \text { to } 1.09] 0.64 & 1.06[0.91 \text { to } 1.23] 0.47
\end{array}
$$

Analysis adjusted for minimisation

factors $^{a}$

Adjusted treatment received $^{b}$

Unadjusted analysis

$$
\begin{array}{r}
0.98[0.88 \text { to } 1.09] 0.70 \\
0.98[0.88 \text { to } 1.09] 0.68
\end{array}
$$$$
1.05 \text { [0.90 to } 1.22] 0.55
$$

Analysis adjusted for minimisation

factors $^{a}$

\footnotetext{
b Adjusted treatment received analysis, adjusted for actual attendance (compliance) with therapy
} 
Table 4

Number of therapy visits attended by men randomised to the intervention groups

\begin{tabular}{lcrrr}
\hline & First visit & Second visit & Third visit & Fourth visit \\
\hline RADICAL(N=205) & & & & \\
Number of men attending & $189(92 \%)$ & $186(91 \%)$ & $177(86 \%)$ & $175(85 \%)$ \\
TURP (N=220) & & & & \\
Number of men attending & $189(86 \%)$ & $173(79 \%)$ & $163(74 \%)$ & $158(72 \%)$ \\
\hline
\end{tabular}


Figure 1a Flow Diagram Trial 1: Radical prostatectomy

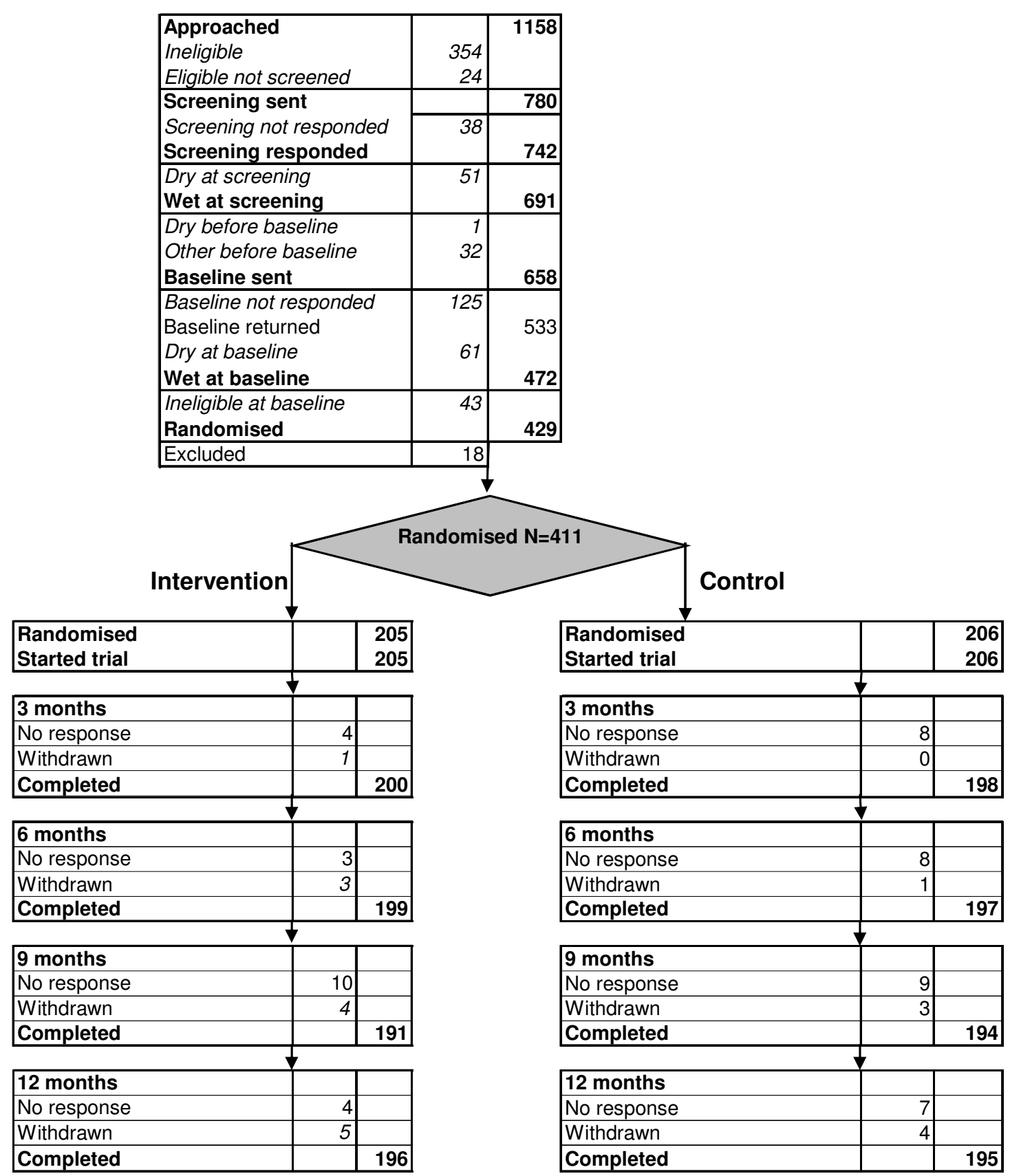


Figure 1b Flow Diagram Trial 2: TURP

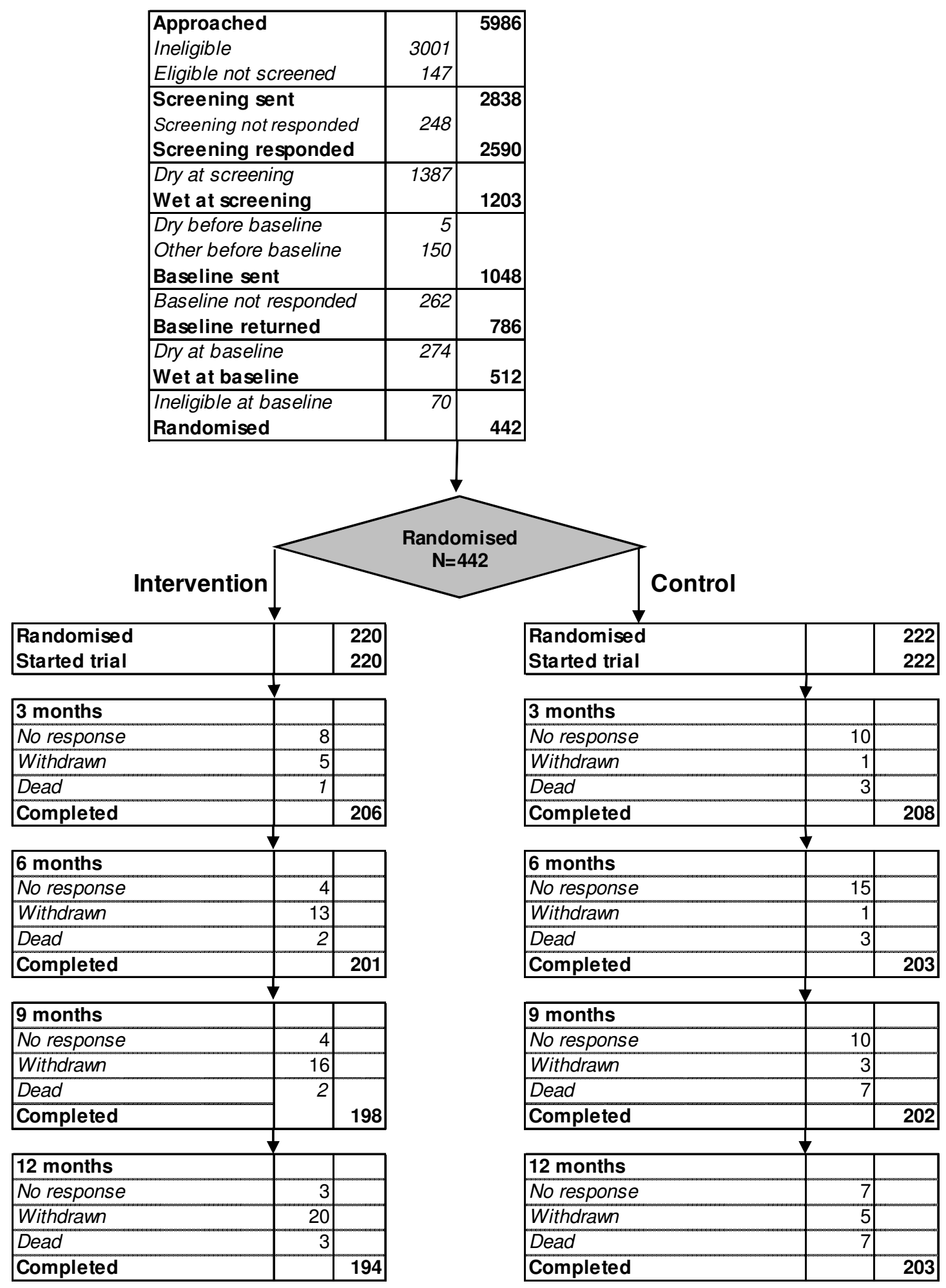

Reasons for withdrawal after randomisation (Int / Control):
IIIness (6 / 2)

Dry (6/1)

No reason or other reason (8/2) 
Figure 2 Percentage of men incontinent and the severity* of the incontinence at each time point

2a: Trial 1 Radical prostatectomy

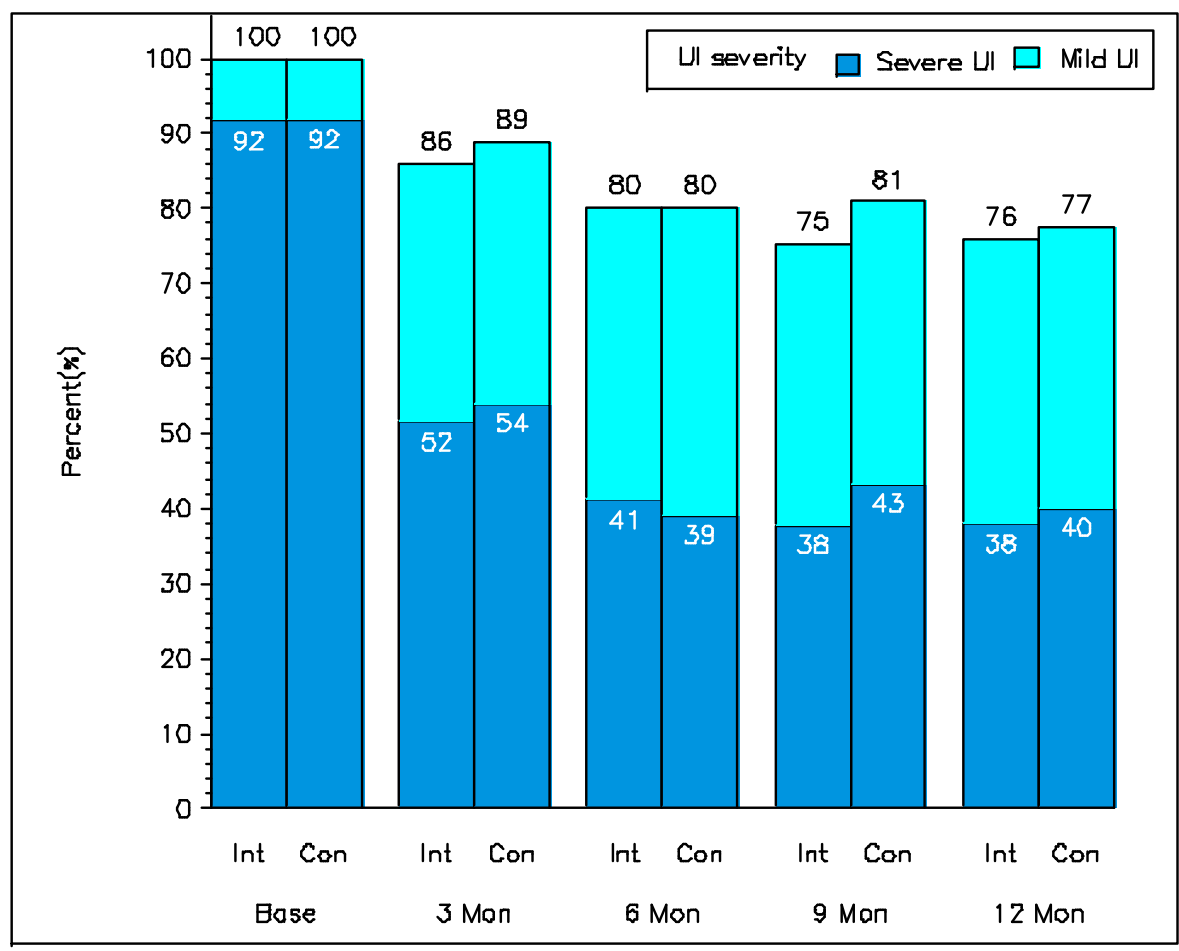

Severe incontinence is defined as at least once a day AND a moderate or large amount of leakage. Int = Intervention group, Con = Control group

$2 \mathrm{~b}:$

Trial TURP

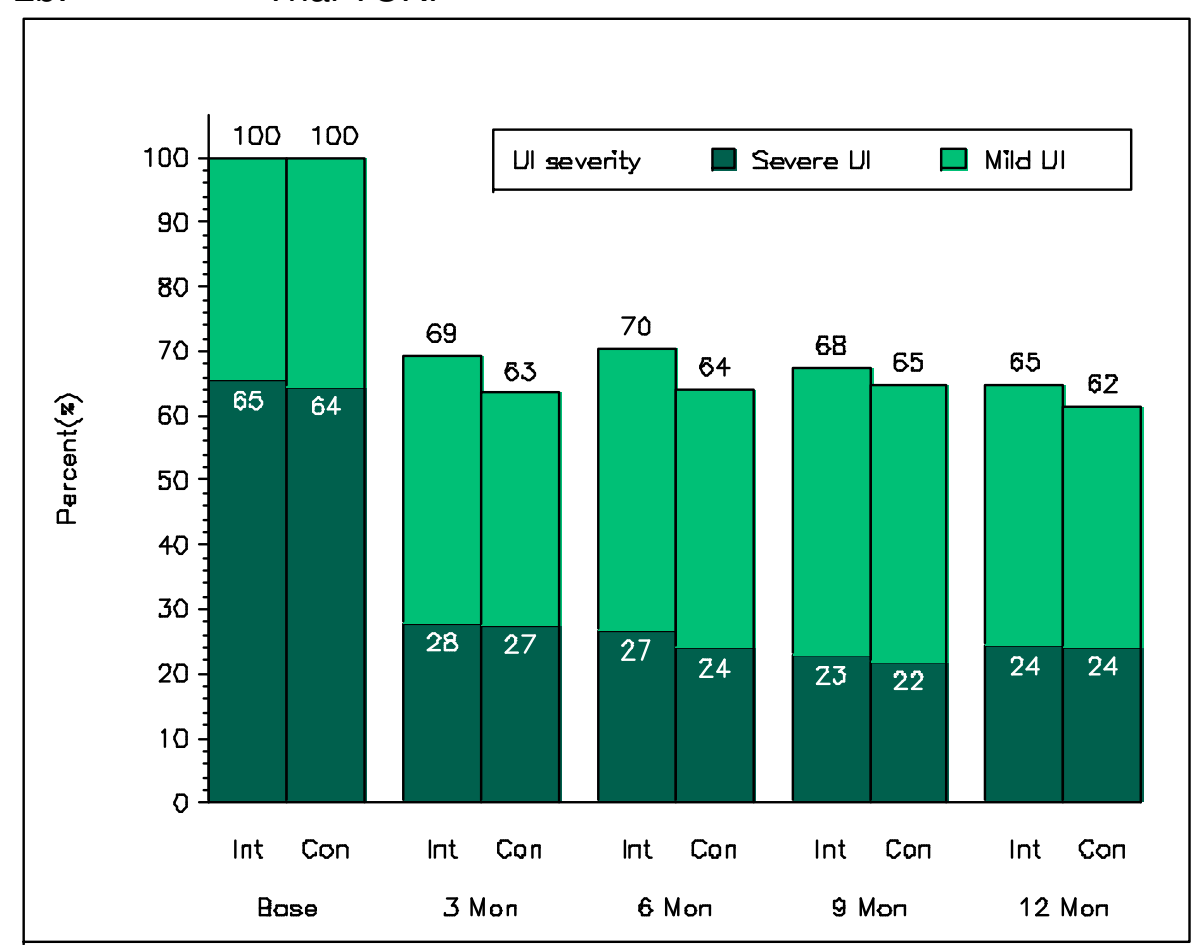

Severe incontinence is defined as at least once a day AND a moderate or large amount of leakage. Int = Intervention group, Con = Control group 
Figure 3 Mean ICIQ Score (+/- SD) at each time point (a higher score = worse incontinence or effect on quality of life)

3a:

Trial 1 Radical prostatectomy

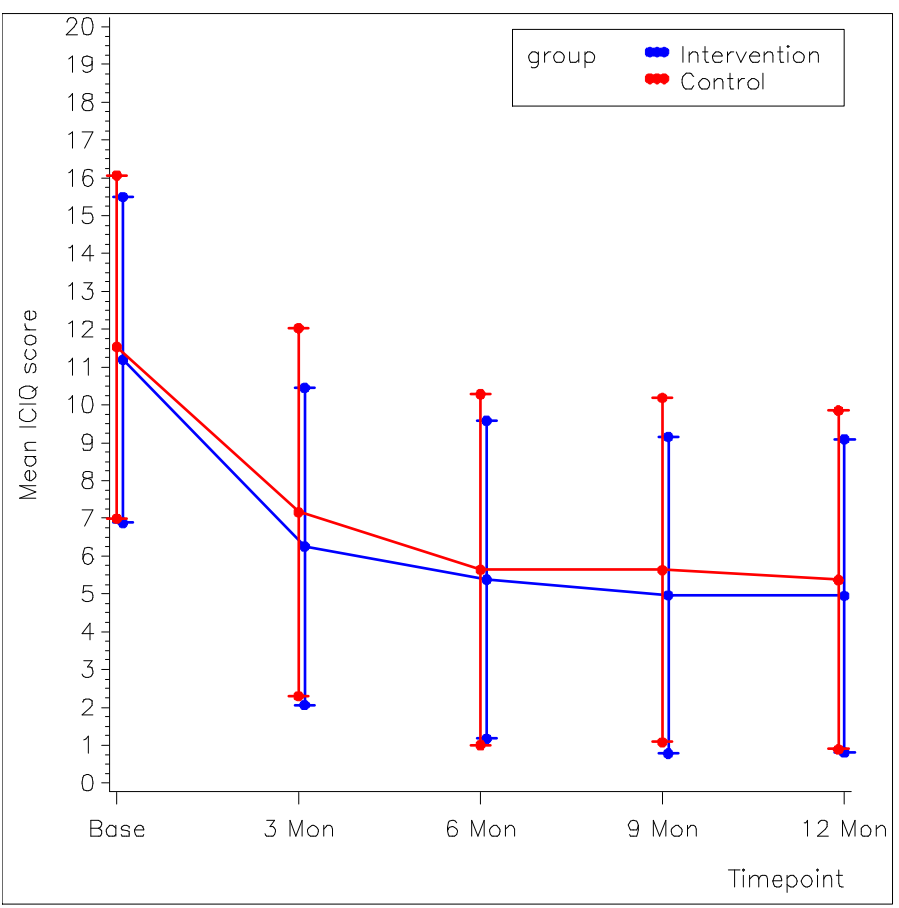

3b:

Trial 2 TURP

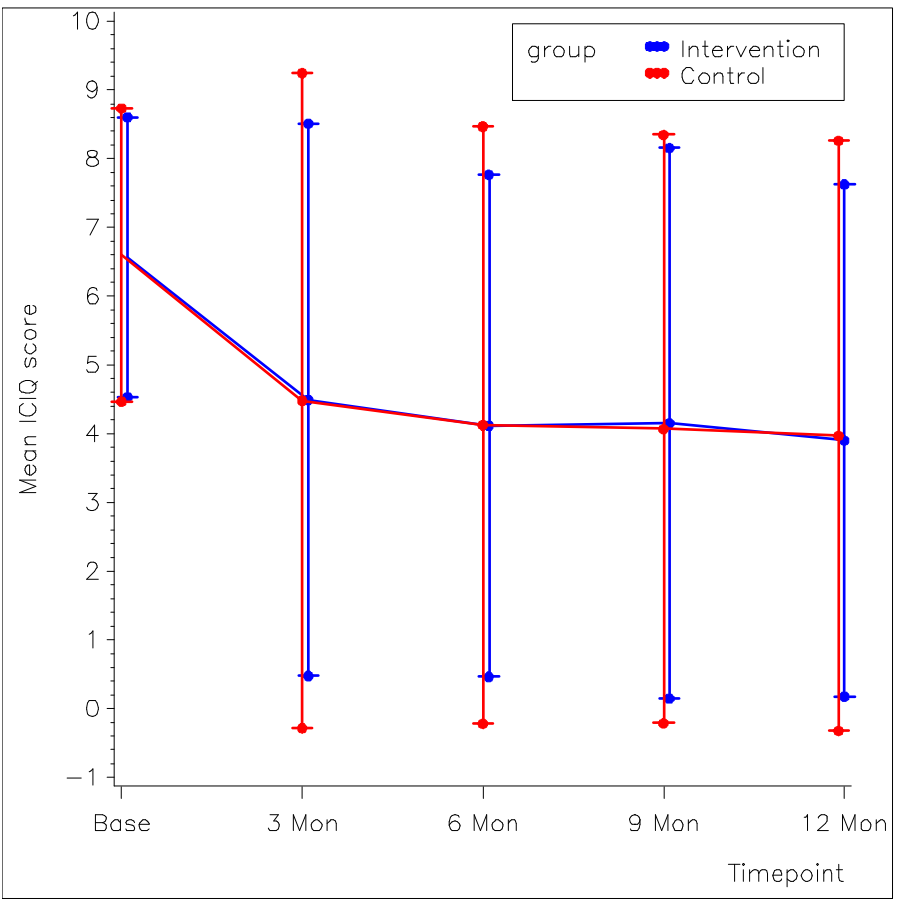


Figure 4 Forest plot of sub group analyses: Urinary Incontinence at 12 months

4a:

Trial 1 Radical prostatectomy

$$
\begin{aligned}
& \text { Leak Before- Yes } \\
& \text { Leak Before-No }
\end{aligned}
$$

Age Category $<=60$

Age Category> 60

BMI Category $<=35$

BMI Category $>35$

Stress UI-Yes

Stress UI-No

Urge UI-Yes
Urge UI-No

Mixed ULY Yes

Mixed UI-No

PML-Yes

PML-No

Other Morbidity-Yes

Other Morbidity-No

Physiotherapist

Nurse
$\mathrm{RR}[99 \% \mathrm{Cl}]$
0.85 [0.62 to 1.15$]$
0.99 [0.85 to 1.15$]$
$0.99[0.76$ to 1.28$]$
0.98 [0.82 to 1.16$]$
$1.00[0.86$ to 1.17$]$
$0.80[0.47$ to 1.34$]$
$0.99[0.85$ to 1.14$]$
0.83 [0.31 to 2.22 ]
0.98 [0.85 to 1.12 ]
1.12 [0.74 to 1.69 ]
0.97 [0.85 to 1.11$]$
1.12 [0.76 to 1.65 ]
$0.94[0.82$ to 1.07$]$
1.39 [0.76 to 2.53 ]
0.94 [0.78 to 1.14$]$
1.04 [0.84 to 1.29 ]
0.91 [0.73 to 1.14$]$
1.02 [0.85 to 1.23 ]

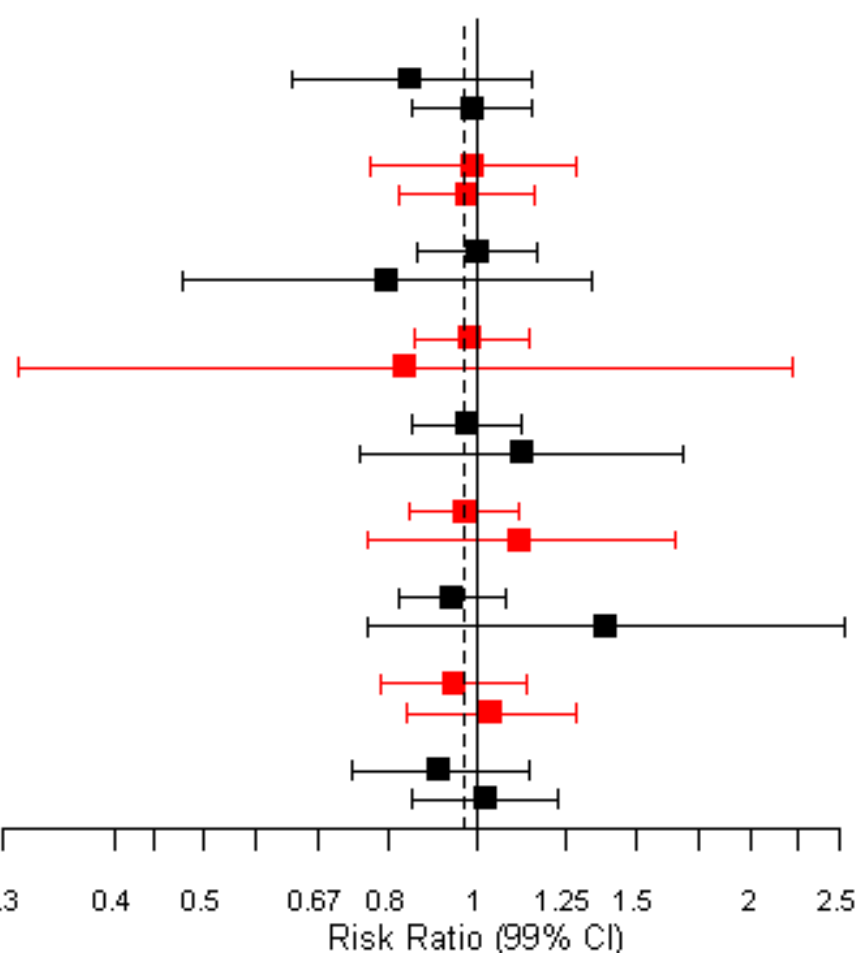

Risk Ratio (99\% Cl)

Overall effect $=0.98,95 \% \mathrm{Cl}[0.88$ to 1.09$]$, represented by broken line.

4b:

Trial 2 TURP

Leak Before-Yes
Leak Before-No

Age Category $<=60$ Age Category> 60

BMI Category $<=35$

BMI Category $>35$

Stress UI-Yes

Stress UI-No

Urge Ul-Yes Urge UI-No

Mixed UI-Yes Mixed UI-No

PML-Yes PML-No

Other Morbidity-Yes Other Morbidity-No

Physiotherapist Nurse
RR [ $99 \% \mathrm{Cl}]$

$1.23[0.95$ to 1.60$]$ 0.89 [0.66 to 1.21 ]

$1.07[0.83$ to 1.37$]$ 1.03 [0.75 to 1.43 ]

$1.08[0.87$ to 1.35$]$ 0.94 [0.60 to 1.47 ]

$1.03[0.82$ to 1.30$]$

1.08 [0.75 to 1.55 ]

1.09 [0.88 to 1.37$]$ 0.91 [0.59 to 1.40$]$

$1.00[0.77$ to 1.28$]$ 1.11 [0.82 to 1.40$]$

1.03 [0.83 to 1.28$]$ 1.16 [0.75 to 1.81$]$

1.08 [0.85 to 1.38$]$ 1.01 [0.72 to 1.42$]$

$1.06[0.81$ to 1.39 ] $1.05[0.79$ to 1.39$]$

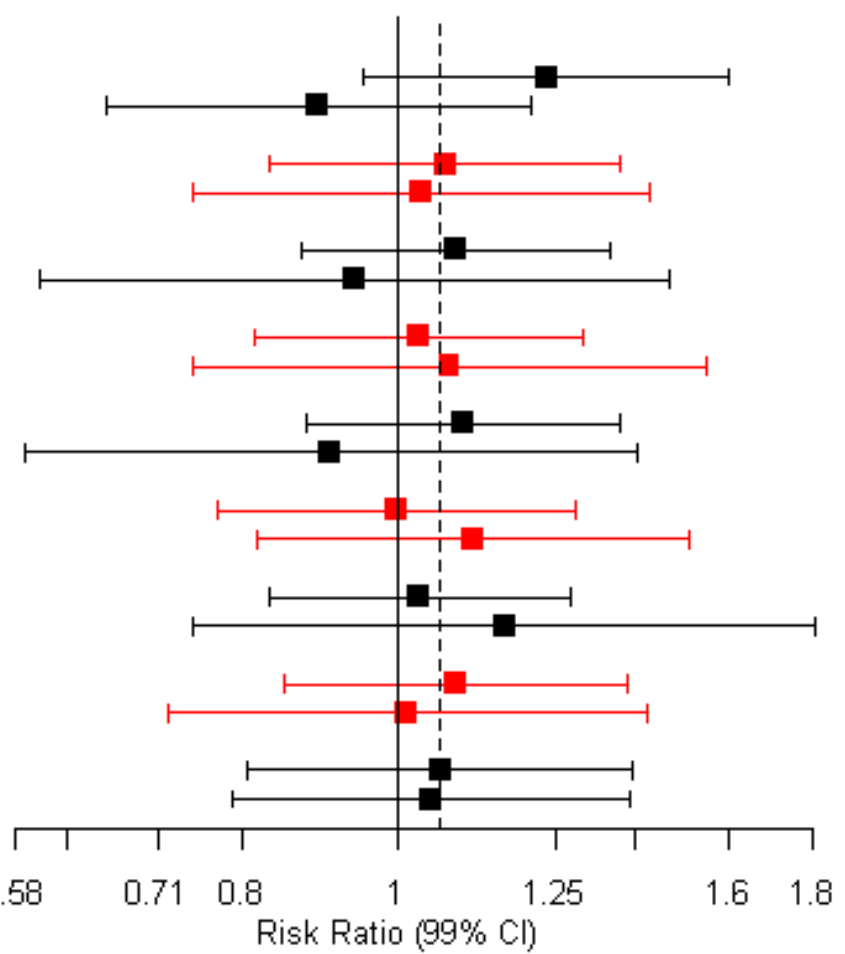

Overall effect $=1.05,95 \% \mathrm{Cl}[0.91$ to 1.22$]$, represented by broken line. 


\section{Explanatory footnote (for Figure 4):}

Leak Before = urinary incontinence before surgery

Stress $\mathrm{UI}=$ stress urinary incontinence at randomisation after surgery

Urge $\mathrm{UI}=$ urgency urinary incontinence at randomisation after surgery

Mixed $\mathrm{UI}=$ both stress and urgency urinary incontinence after surgery

$\mathrm{PML}=$ post-micturition leakage at randomisation after surgery

Other morbidity $=$ participant with other health problems at randomisation

Physiotherapist $/$ Nurse $=$ professional background of therapist delivering intervention 


\section{Reference List}

(1) Lourenco T, Armstrong N, Nabi G, Deverill M, Pickard R, Vale L, et al. Systematic review and economic modelling of effectiveness and cost utility of surgical treatments for men with benign prostatic enlargement (BPE). Health Technology Assessment 2008;12(35).

(2) Lourenco T, Pickard R, Vale L, Grant A, Fraser C, MacLennan G, et al. Alternative approaches to endoscopic ablation for benign enlargement of the prostate: systematic review of randomised controlled trials. BMJ 2008;337.

(3) Armstrong N, Vale L, Deverill M, Nabi G, McClinton S, N'Dow J, et al. Surgical treatments for men with benign prostatic enlargement: cost effectiveness study. BMJ 2009;338.

(4) Sanda MG, Dunn RL, Michalski J, Sandler HM, Northouse L, Hembroff L, et al. Quality of life and satisfaction with outcome among prostate-cancer survivors. New England Journal of Medicine 2008 Mar 20;358(12):1250-61.

(5) Smith DP, King MT, Egger S, Berry MP, Stricker PD, Cozzi P. Quality of life three years after diagnosis of localised prostate cancer: population based cohort study. BMJ 2009;339:4817.

(6) Milsom I, Altman D, Lapitan MC, Nelson R, Sillen U, Thom D. Epidemiology of urinary ( $\mathrm{UI})$ and faecal $(\mathrm{FI})$ incontinence and pelvic organ prolapse (POP). Incontinence: 4th International Consultation on Incontinence. 4th ed. Paris, France: Health Publication Ltd; 2009. p. 35-112.

(7) DuMoulin C, Hay-Smith EJ. Pelvic floor muscle training versus no treatment, or inactive control treatments, for urinary incontinence in women. Cochrane Database of Systematic Reviews 2010;CD005645(1).

(8) Imamura M, Abrams P, Bain C, Buckley B, Cardozo L, Cody J, et al. Systematic review and economic modelling of the effectiveness and costeffectiveness of non-surgical treatments for women with stress urinary incontinence. Health Technology Assessment 2010;14(40).

(9) Hunter KF, Moore KN, Glazener CMA. Conservative management for postprostatectomy urinary incontinence. Cochrane Database of Systematic Reviews 2007;(2).

(10) Wallace SA, Roe B, Williams K, Palmer M. Bladder training for urinary incontinence in adults. Cochrane Database of Systematic Reviews 2009;(1).

(11) Abrams P, Avery K, Gardener N, Donovan J, on behalf of the ICIQ Advisory Board. The International Consultation on Incontinence modular questionnaire: www.iciq.net. J Urol 2006;175:1063-6.

(12) Dorey G, Glazener C, Buckley B, Cochran C, Moore K. Developing a pelvic floor muscle training regimen for use in a trial intervention. Physiotherapy 2009 Sep;95(3):199-209.

(13) Kind P, Hardman G, Macran S. UK Population norms for EQ-5D. York, UK: University of York; 1999. 
(14) Zou G. A modified poisson regression approach to prospective studies with binary data. American Journal of Epidemiology 2004;159(7):702-6.

(15) White IR. Uses and limitations of randomization-based efficacy estimators. Statistical Methods in Medical Research 2005;14(4):327-47.

(16) Nagelkerke N, Fidler V, Bernsen R, Borgdorff M. Estimating treatment effects in randomized clinical trials in the presence of non-compliance. Statistics in Medicine 2000;19(14):1849-64.

(17) Department of Health. NHS Reference Costs. http://www dh gov uk/en/publicationandstatistics/publication/publicationspolicyandguidance 2009 [cited 2009 Nov];

(18) National Health Service (NHS) in Scotland Information and Statistics Division (ISD). Scottish Health Services Costs. http://www isdscotland org/isd 2009 [cited 2009 Nov];

(19) Department of Transport. COBA 9 Manual. London Department of Transport; 1989.

(20) HM Revenue and Customs. EIM31240 - Employees using own vehicles for work: statutory mileage rates 2002/03 onwards: kinds of vehicle. http://www hmrc gov uk 2009

(21) The Bank of England. The Bank of England. www thebankofengland co uk 2010 October 13 [cited 2010 Oct 13];

(22) Staskin D, Kelleher C, Avery K, Bosch R, Cotterill N, Coyne K, et al. Patientreported outcome assessment. Incontinence: 4th International Consultation on Incontinence. 4th ed. Paris, France: Health Publication Ltd; 2009. p. 363412.

(23) Frankel SJ, Donovan JL, Peters TI, Abrams P, Dabhoiwala NF, Osawa D, et al. Sexual dysfunction in men with lower urinary tract symptoms. Journal of Clinical Epidemiology 1998 Aug;51(8):677-85.

(24) Floratos DL, Sonke GS, Rapidou CA, Alivizatos GJ, Constantinides CA, Delibeliotis $C$. Biofeedback versus verbal feedback as learning tools for pelvic muscle exercises in the early management of urinary incontinence after radical prostatectomy. British Journal of Urology International 2002;89(7):7149.

(25) Van Kampen M, De Weerdt W, Van Poppel H, Feys H, Campesino AC, Stragier $J$, et al. Prediction of urinary continence following radical prostatectomy. Urologia Internationalis 1998;60(2):80-4.

(26) Moore KN, Valiquette L, Chetner MP, Byrniak S, Herbison GP. Return to continence after radical retropubic prostatectomy: A randomized trial of verbal and written instructions versus therapist-directed pelvic floor muscle therapy. Urology 2008;72(6):1280-6.

(27) Manassero F, Traversi C, Ales V, Pistolesi D, Panicucci E, Valent F, et al. Contribution of early intensive prolonged pelvic floor exercises on urinary continence recovery after bladder neck-sparing radical prostatectomy: Results of a prospective controlled randomized trial. Neurourol Urodyn 2007;26(7):985-9. 


\section{Appendix}

\section{MAPS Principal Investigators in Centres}

Mr Muhammad Akhtar, Mr Prasad Bolina, Mr Sudhir Borgaonkar, Mr Gregory Boustead, Mr Derek Byrne, Mr Shiv Bhanot, Mr David Chadwick, Mr Noel Clarke, Mr Owen Cole, Mr Gerald Collins, Professor James N'Dow, Mr Peter Donaldson, Mr

Roland Donat, Mr lan Eardley, Mr David Gillatt, Mr Tahseen Hasan, Prof Howard Kynaston, Mr Pradip Javle, Ms Ling Lee, Mr Malcolm Lucas, Mr Ruairidh MacDonagh, Mr John MacFarlane, Mr Peter Malone, Mr Robert Meddings, Mr Geoffrey Orr, Mr Anup Patel, Mr Rajendra Persad, Mr Nigel Philp, Mr Alvan Pope, Mr Tim Porter, $\mathrm{Dr}$ Derek Rosario, $\mathrm{Mr}$ Naeem Shaikh, $\mathrm{Mr}$ Subramanian Kanagasundaram, Mr James Tweedle, Mr Mohammad Vandal and Mr Ralph Webb.

\section{MAPS Recruitment Officers in Centres}

Vanessa Adamson, Paul Allcoat, Margaret Austin, Irene Blythe, Aelens Brauckman, Vikram Bohra, Ruth Broom, Andrew Brown, Clare Buckley, Jo Butler, Jenny ButlerBarnes, Loveness Chikopela, J Connell, Helen Corderoy, Kirsty Crozier, Liz Dalgaty, M Davies, Debbie Delgado, Gill Driver, Lisa Egan, Charlotte Etheridge, Alison Finlay, Linda Fowler, Chris Garlick, Claire Gaskell, Debbie Gibbons, Louise Gray, Jane Griffiths, Andrew Harvey, Sam Genner, Louise Goodwin, Delyth Hague, Mary Hamilton, Lisa Hardstaff, Samantha Holliday, Gillian Hornzee, Joanne Howson, Peter Holding, Katrina Hurley, C Jones, Laura Jones, Louise Jones, Suriya Kirkpatrick, Gill Larsen, Lorraine Lamb, Angela Lee, Julie Longworth, Brenda McCallum, Patricia McClurey, Marilyn McCurrie, Sarah McKenna, Carolyn Mansfield, Barbara Mayne, Mariam Nasseri, Neale O'Brien, Christine Oxnard, K Pearce, Linda Pennet, Valerie Powell, Kathryn Procter, Navin Ravindranath, Kez Richards, Kathleen Riddle, Paul Ridley, Stephanie Ridgway, Allison Robertson, Wendy Robson, Lisa Saville, Mary Simpson, Alison Steel, Andy Smallwood, Dorothy Sugden, Louise Taylor, Jill Taylor, Sarah Thompson, Nona Toothill, Barbara Townley, Karen Wilmott and Jill Youd. 


\section{Maps Therapists in Centres}

Margaret Atherton, Annette Bell, Jill Branson, James Bolarin, Elaine Cathcart, Ada

Cardiff, Alison Coughlan, Debbie Delgardo, Ann Evans, Alison Finlay, Madeline Frank, Ann Gilchrist, Caroline Gill, Louise Goodwin, Sue Hallam, Linda Haworth, Kay Hildersley, Philip Howard, Fiona Jarvis, Fiona Key, Gill Larsen, Lorraine Lamb, Fiona Lennard, Maureen Lumber, Kath Moore, Kirsty Moore, Julia Muman, Mariam Nasseri, Linda Pennet, Valerie Powell, Debbie Rigby, Allison Robertson, Karen Wilmott, Ann Yeats and Jill Youd. 